\title{
Retrospective Analysis of Various Reproductive Disorders of Mares in Punjab, India
}

\author{
Jugraj Singh Mahal*, Mrigank Honparkhe and Ajeet Kumar \\ Department of Veterinary Gynaecology and Obstetrics, Guru Angad Dev Veterinary and Animal Sciences University, \\ Ludhiana, Punjab, INDIA \\ *Corresponding author: JS Mahal; E-mail: jugrajmahal30@gmail.com
}

Received: 30 July, 2021

Revised: 02 Sept., 2021

Accepted: 06 Sept., 2021

\begin{abstract}
A retrospective data were analyzed to investigate the incidence of various reproductive disorders of indigenous mares $(n=150)$ at various animal fairs and organized private stud farms of Punjab during the period of last five years (2013 to 2017). A common questionnaire was prepared to generate information regarding various fertility parameters for breeding practices, $\%$ barren mares, \% maiden mares and pregnancy losses during different stages of gestation. The reproductive parameters (estrus/ mareyear, estrus/foaling, mating/mareyear, mating/estrus, mating/foaling) were calculated for 750 mare year, using SPSS software (version 16.00). The comparison of data was done using Hosmer and Lemesaw test, Logistic Regression and One-way ANOVA. Amongst 2,949 oestrous cycles in five years, $2,296(77.86 \%)$ were spontaneous whereas $653(22.14 \%)$ were induced with exogenous hormones. Out of 2296 spontaneous estruses, $426(18.55 \%)$ were foal heats. The overall Mean values of estrus/ mare year, estrus/foaling, mating/mare year, mating/estrus, mating/foaling were 3.93, 1.94, 1.78, 1.63 and 1.72, respectively. There was non-significant $(\mathrm{P} \geq 0.05)$ difference observed for these reproductive parameters during five years of period. The percentage of barren mares increased significantly $(\mathrm{P}<0.05)$ whereas, the percent foaling mares decreased significantly $(\mathrm{P}<$ 0.05 ) during last five years. An early stage of gestation (17-35 days) was more prone (3.47\%) for the pregnancy losses followed by the stage at 30-60 days of gestation $(2.27 \%)$. Pregnancy losses during these stages were significantly $(\mathrm{P}<0.05)$ higher as compared to later stage of gestation.
\end{abstract}

\section{HIGHLIGHTS}

(0 To investigate incidence of various reproductive disorders in mares of Punjab.

0 There was increasing number of barren mares and decreasing number of foaling mare.

( The data generated out of this study would be helpful for planning of breeding strategies and to take suitable measures to curtail the reproductive disorders.

Keywords: Barren mare, foaling mare, foaling rate, pregnancy loss, uterine torsion, dystocia

The horse (Equuscaballus) has been reared in India since the ancient times for various purposes like hunting, drafting, equestrian sports, races and other traditional activities The horses and ponies contribute $0.12 \%$ of total livestock population in India $\left(19^{\text {th }}\right.$ livestock census 2014). The horses and ponies population in the country is 0.62 million including 0.350 million males and 0.275 million females. During last decade, the total population of horses and ponies has increased by $2.08 \%$. The number of females is decreased by 0.036 million over the previous census. Punjab ranks $7^{\text {th }}$ for horses and ponies population and contributes $5.26 \%$ of the total population of horses and ponies. In Punjab, horses and ponies population was 32,860 with 14,124 males and 18,736 females $\left(19^{\text {th }}\right.$ livestock census 2014).

How to cite this article: Mahal, J.S., Honparkhe, M. and Kumar, A (2021). Retrospective Analysis of Various Reproductive Disorders of Mares in Punjab, India. J. Anim. Res., 11(05): 863-868.

Source of Support: None; Conflict of Interest: None 
Mares suffer from a variety of reproductive issues, including repeat breeding, anestrus, abortions, retention of placenta and dystocia etc. in light of fact that the species' population has expanded over the past decade, it is necessary to analyze a current situation of various reproductive disorders in province of Punjab. The reproductive disorders might result in complete or partial reproductive failure, resulting in financial losses for stud farmers (Durrani and Kamal, 2009). In mares, different types of uterine infection can cause abortion at various stages of gestation in mares. Abortion remains a major cause of economic loss for horse breeders. The frequency of equine abortions is estimated to be $8-19 \%$ (Laugier et al., 2011). Besides these various obstetrical problems are also a major concern in mare reproduction. Most of the studies regarding retrospective analysis of reproductive disorders have been conducted for thoroughbred mare (Morris and Allen, 2002; Sharma et al., 2010; Benko et al., 2015) while such studies are still lacking in indigenous breeds of mares. Therefore, the current study was designed to gather and retrospectively analyze the data regarding reproductive status in indigenous mares for the last five years period (2013-2017).

\section{MATERIALS AND METHODS}

A total of 150 indigenous mares were included in this study. Which were raised on various organized stud farms and animal fairs in Punjab, where breeding data kept up to date for the previous breeding seasons (i.e. from 20132017). The required information was gathered through a questionnaire. The age of the mares, foaling status, services dates, pregnancy status at different intervals, day of foaling, estrus record (whether occurred spontaneous or hormonally induced) were gathered. The detailed information regarding obstetrical complications such as uterine torsion, dystocia due to abnormal presentations, positions and postures, history of caesarean section and retention of placenta was also incorporated. The study included mares with complete breeding record. Since most of the mares returned to the same stud farm for several years and used for breeding for more than one breeding season, the conventional term mare year was employed in the study. A literal meaning of mare year is the specific month of a year (covering season) in which mares allowed to cover. Accordingly, the data was available and analyzed for 750 mare year (150 mares $\times 5$ years).
On the basis of reproductive status of a mare, various terms were used as: Sharma et al. (2010):

1. Maiden: A term in the specific breeding sense be used only for any filly or mare which has never been covered/mated by a stallion in spite of attaining puberty and sexual maturity.

2. Barren : The mare that mated many a times but didn't conceive at end of last breeding season ora mare bred several cycles in a season without pregnancy.

3. Foaling mare: Pregnant females which carries foetus to full term

4. Aborted mare: The mare that became pregnant at end of last breeding season but did not foal and miscarried.

5. Rested: A parous mare that deliberately not mated during the last breeding season due to avoiding of late foaling in next breeding season as early foal having good market value. Mares with excellent pedigree when comes to the situation of breeding in last months of breeding season are given voluntary rest by the breeder to be bred early in the next breeding season.

6. Mare year: Specific months of a year (breeding season) in which thoroughbred mares were allowed for covering. In India mare year starts from $\left(1^{\text {st }}\right.$ January to 15 may).

The routine practice for detection of estrus during the breeding season was done by estrous behavior and male teasing.

Various reproductive parameters considered in this study were described as- Sharma et al. (2010):

1. Estrus/mare year: The total number of observed estrus shown by a mare in breeding season (mare year).

2. Estrus/foaling: The number of estrus required by mare to become pregnant.

3. Mating/mare year: The total number of mating offered to a mare in a particular breeding season.

4. Mating/estrus: The number of mating offered to a mare in particular estrus.

5. Mating/foaling: The number of mating required by a mare to become pregnant in a particular breeding season. 
6. Intrauterine treatment /estrus: The number of times the intrauterine treatments given to mare during estrus in a particular breeding season.

The pregnancy losses during different stages of gestation was estimated as:

$\square \quad 17$ to 30 days, 30-60 days, 60-90 days, 90-210 days and 210 days to live foaling.

The data were analyzed using SPSS software (version 16). The reproductive parameters were represented as mean values. The comparison of data during last five years was done using Hosmer and Lemesaw test, Logistic Regression, one way ANOVA. The values were considered significant if $\mathrm{P} \leq 0.05$.

\section{RESULTS AND DISCUSSION}

During 750 mare years, 1336 total mating was recorded and of these 385 was successfully foaled. The overall foaling/mare year percentage was $51.33 \%$ from year 2013 to 2017 and foaling rate was $28.8 \%$. Sairanen et al. (2009) observed that the average foalingrates varied between $66.3 \%$ to $72.6 \%$ instandar bred and the Finhorse trotters. The retrospective data of seven years analyzed by Sharma et al. (2010). The overall pregnancy rate at day 16 and overall foaling rates were $50.30 \%$ and $68.95 \%$, respectively and were significantly higher in mares aged 3-7 years than $\geq 18$ years old mares revealed the service records of 253 Thoroughbred mares (1181 mare years) from nine organized Thoroughbred stud farms, situated in the subtropical northwestern India and assessed their reproductive performance. Relatively low foaling rates in present study might attributed to the mating type, the age and breeding type of the mare, and the age of the stallion (Sairanen et al., 2009)

Different reproductive parameters such as oestrus/mare year, oestrus/foaling, mating/mare year, mating/oestrus, mating/foaling, uterine treatment/oestrus were calculated as mean for each year and depicted in Table 1. The overall mean values of oestrus/mare year, oestrus/foaling, mating/mareyear, mating/oestrus, mating/foaling were $3.93,1.94,1.78,1.63,1.72$, respectively. The year wise comparison of these parameters revealed non-significant difference amongst various years suggestive of not much change in these parameters over the period of last five years. The overall meanvalue of intrauterine treatment/ estrus was 9.2 and it was also non-significant as per yearwise comparison (Sharma, 2005) documented effects of reproductive status on measures of reproductive efficiency in Thoroughbred mares. In this study, the overall mean for estrus/mare year, estrus/foaling, mating/mare year, mating/estrus, mating/foaling and uterine treatment/estrus were $1.76,2.60,2.95,1.68,4.37$ and 12.65 , respectively.

In our study, a mare required on an average 1.94 oestrus to produce a live foal, which is slightly higher than study of Hemberg et al. (2004) and reflects slightly lower fertility in the broodmares of Punjab may be attributing to inefficient management as compared to other developed countries. The overall number of matings per oestrus recorded in present study is higher (1.63) as compared to that (1.12) quoted by Morris and Allen. (2002) in Thoroughbred. This might be due to best management in thoroughbred farms as compared indigenous breed stud farm. The record of mean number of treatments per estrous was 9.2 in the present study that yielded $6.1 \%$ by (Morris and Allen, 2002) documented that intrauterine treatments were given in $12.24 \%$ estrous cycles in thoroughbred mare and included saline lavage, infusion of antibiotics and parenteral administration of oxytocin to aid expulsion of accumulated uterinefluid. There were significant differences in the proportions of mares given uterine therapy by veterinarians, but there were no differences in the proportion of mares who became pregnant by clinicians (Morris and Allen, 2002).

Table 1: Mean values for various reproductive parameters in mares over the period of 5 years in Punjab

\begin{tabular}{llllllll}
\hline $\begin{array}{l}\text { Sl. } \\
\text { No. }\end{array}$ & Parameters & $\mathbf{2 0 1 3}$ & $\mathbf{2 0 1 4}$ & $\mathbf{2 0 1 5}$ & $\mathbf{2 0 1 6}$ & $\mathbf{2 0 1 7}$ & $\begin{array}{l}\text { Overall } \\
\text { mean }\end{array}$ \\
\hline 1 & Estrus/mare year 4.29 & 3.74 & 3.73 & 3.85 & 4.06 & 3.93 \\
2 & Estrus/ Foaling & 2.21 & 1.91 & 1.79 & 1.90 & 1.92 & 1.94 \\
3 & $\begin{array}{l}\text { Mating/ Mare } \\
\text { year }\end{array}$ & 1.73 & 1.70 & 1.66 & 1.87 & 1.94 & 1.78 \\
4 & & & & & & \\
5 & Mating/ Estrus & 1.62 & 1.63 & 1.61 & 1.69 & 1.64 & 1.63 \\
6 & Mating/ Foaling & 1.86 & 1.68 & 1.72 & 1.65 & 1.69 & 1.72 \\
7 & Treatment/ Estrus 11.0 & 7.0 & 8.0 & 9.0 & 11.0 & 9.2 \\
\hline
\end{tabular}

Values in the table have no significant differences.

The mares were divided into different groups on their reproductive status, which included barren, foaling, 
maiden, rested and aborted. Table 2 contains information on the data of a retrospective investigation of reproductive status of the mares of Punjab. It revealed that percent of barren mares were significantly increased $(\mathrm{P}<0.05)$ from 2013 to 2017 and varied between $12.66 \%$ in 2015 to $24.0 \%$ in 2017 . The percentage of foaling mares were significantly decreased that was highest in 2015 (57.33\%) and lowest in 2017 (45.33\%). The mean values of barren and foaling mares in last 5 years (2013-2017) were 19.06 and 51.33 respectively. The mean \% for maiden, rested and aborted mares were $13.73,7.32$ and 8.53 , respectively. There was no significant difference in percent of maiden, rested and aborted mares during 5 year survey data.

Hemberg et al. (2004) reported the proportion of barren mares as $22.1 \%$ which was nearly similar to the present study $(19.06 \%)$, however, the proportion of maiden and faoling mares was higher (15.6\% and $58.9 \%)$ as compared to our study $(13.73 \%$ and $51.33 \%)$. The managemental conditions play pivotal role in increasing or decreasing trend of barren and foaling mares (Morris and Allen, 2002). Bosh et al. (2009) reported the proportion of maiden, foaling and barren mares was 15.4, 70.3 and $14.2 \%$, respectively and there were differences in the proportion of mares by reproductive status among the farms $(\mathrm{P}<0.0001)$. Similar observations as in our study were quoted by Katila et al. (2010) about the decreasing proportion of foaled mares and increasing barren mares during 15-year survey of reproductive efficiency of Standard bred (SB) and Finnhorse (FH) trotters in Finland. This study mentioned a decreasing trend in foaling rates of both breeds. Over the 15 years period, the proportion of foaled mares decreased from 46 to $30 \%$ in the $\mathrm{FH}$ and from 53 to $39 \%$ in the SB. The proportion of barren mares increased in both breeds (24.7 to $29.5 \%$ in $\mathrm{FH}$ and 18.5 to $24.4 \%$ ), but no changes were observed in the maiden mares. The rested mare proportion in $\mathrm{FH}$ varied between 9.6 to $18.6 \%$ while in SB it was 8.1 to $13.9 \%$.

The incidence of pregnancy losses during different stages of gestation were estimated at 17 to 30 days, 30-60 days, 60-90 days, 90-210 days and 210 days to live foaling and were shown in Table 3 . The overall pregnancy loss was significantly higher $(\mathrm{P}<0.05)$ during early phase $(17$ 30 days) of gestation (3.47\%) followed by during 30-60 days $(2.27 \%)$. It was revealed from the study that as the gestation length increased the pregnancy losses were reduced. There was no pregnancy loss recorded from 210 days gestation till foaling. Allen et al. (2007) also reported more pregnancy loss during early stages followed by middle and late stage pregnancy which is in accordance with present study. Morris and Allen. (2002) reported pregnancy loss during 15 - 35 days as $10.39 \%$ followed by $2.18 \%$ during late pregnancy. The pregnancy losses

Table 2: Retrospective analysis of reproductive status of mares in Punjab

\begin{tabular}{lllllll}
\hline Type of mares & $\mathbf{2 0 1 3}$ & $\mathbf{2 0 1 4}$ & $\mathbf{2 0 1 5}$ & $\mathbf{2 0 1 6}$ & $\mathbf{2 0 1 7}$ & Overall Mean \\
\hline Barren (\%) & $20.66^{\mathrm{a}}(31 / 150)$ & $18.00^{\mathrm{a}}(27 / 150)$ & $12.66^{\mathrm{c}}(19 / 150)$ & $20.02^{\mathrm{a}}(30 / 150)$ & $24.00^{\mathrm{b}}(36 / 150)$ & $19.07(143 / 750)$ \\
Foaling (\%) & $51.33^{\mathrm{a}}(77 / 150)$ & $52.00^{\mathrm{a}}(78 / 150)$ & $57.33^{\mathrm{b}}(86 / 150)$ & $50.66^{\mathrm{a}}(76 / 150)$ & $45.33^{\mathrm{c}}(68 / 150)$ & $51.33(385 / 750)$ \\
Maiden (\%) & $14.00(21 / 150)$ & $13.33(20 / 150)$ & $12.00(18 / 150)$ & $14.66(22 / 150)$ & $14.66(22 / 150)$ & $13.73(103 / 750)$ \\
Rested (\%) & $6.66(10 / 150)$ & $7.33(11 / 150)$ & $8.66(14 / 150)$ & $7.33(11 / 150)$ & $6.66(10 / 150)$ & $7.47(56 / 750)$ \\
Aborted (\%) & $7.33(11 / 150)$ & $9.33(14 / 150)$ & $9.33(14 / 150)$ & $7.33(11 / 150)$ & $9.33(14 / 150)$ & $8.53(64 / 750)$ \\
\hline
\end{tabular}

a,b,c-values with different supercripts in a row differ significantly $(\mathrm{P}<0.05)$.

Table 3: \% Incidence of pregnancy losses during different stages of gestation

\begin{tabular}{lllllll}
\hline Stages of gestation & $\mathbf{2 0 1 3}$ & $\mathbf{2 0 1 4}$ & $\mathbf{2 0 1 5}$ & $\mathbf{2 0 1 6}$ & $\mathbf{2 0 1 7}$ & Overall \% pregnancy loss \\
Days 17-30 & $3.33(5 / 150)$ & $4(6 / 150)$ & $3.33(5 / 150)$ & $2.66(4 / 150)$ & $4(6 / 150)$ & $3.47^{\mathrm{b}}(26 / 750)$ \\
Days 30-60 & $2(3 / 150)$ & $2(3 / 150)$ & $2.66(4 / 150)$ & $2(3 / 150)$ & $2.66(4 / 150)$ & $2.27^{\mathrm{b}}(17 / 750)$ \\
Days 60-90 & $1.33(2 / 150)$ & $2(3 / 150)$ & $2(3 / 150)$ & $0.66(1 / 150)$ & $1.33(2 / 150)$ & $1.47^{\mathrm{a}}(11 / 750)$ \\
Days 90-210 & $0.66(1 / 150)$ & $0.66(1 / 150)$ & $0.66(1 / 150)$ & $1.33(2 / 150)$ & $0.66(1 / 150)$ & $0.80^{\mathrm{a}}(8 / 750)$ \\
Days 210- foaling & $0(0 / 150)$ & $0(0 / 150)$ & $0(0 / 150)$ & $0(0 / 150)$ & $0(0 / 150)$ & 0 \\
\hline
\end{tabular}

a,b_Values with different superscripts differed significantly $(\mathrm{P}<0.05)$ in a column. 
Table 4: Per cent incidence of obstetrical complications in mares during last five years ( $n=150 /$ year)

\begin{tabular}{llllllll}
\hline SI. No. & Complications & $\mathbf{2 0 1 3}$ & $\mathbf{2 0 1 4}$ & $\mathbf{2 0 1 5}$ & $\mathbf{2 0 1 6}$ & $\mathbf{2 0 1 7}$ & Overall Mean \\
\hline 1 & $\begin{array}{l}\text { Dystocia (due to abnormal } \\
\text { presentations, position and postures) }\end{array}$ & $2^{\mathrm{a}}(3 / 150)$ & $2.6^{\mathrm{a}}(4 / 150)$ & $3.33^{\mathrm{a}}(5 / 150)$ & $2.6^{\mathrm{a}}(4 / 150)$ & $4.6^{\mathrm{b}}(7 / 150)$ & $3.073(23 / 750)$ \\
& & & & & & \\
2 & $\begin{array}{l}\text { Retention of placenta } \\
3\end{array}$ & $5.33(8 / 150)$ & $4(6 / 150)$ & $4(6 / 150)$ & $4(6 / 150)$ & $4(6 / 150)$ & $4.274(32 / 750)$ \\
\hline
\end{tabular}

Values in a row with different superscript varies significantly $(\mathrm{P}<0.05)$.

in mares are more commonly associated with problem of the umbilical cord, comprising umbilical cord torsion and the long cord/cervical pole ischaemia disorder (Smith et al., 2003). The infectious causes involved are bacteria $(79.9 \%)$, followed by viruses $(15.1 \%)$ and then fungi $(1.8 \%)$. The non-infective causes of abortion or neonatal death included twinning (6.0\%), intrapartum still birth $(13.7 \%)$ and placentitis associated with infection $(9.8 \%)$ (Smith et al., 2003; Laugier et al., 2011).

Sharma et al. (2011) observed overall pregnancy losses in thoroughbred mares with and without intrauterine treatment as $21.95 \%$ versus $18.55 \%$ respectively. The pregnancy losses in lactating and barren mares were $8 \%$ and $17.8 \%$ from $16-39$ days of pregnancy whereas during days 39 -term the losses were $10 \%$ in each respectively. This corroborated our findings of increased percent of pregnancy loss during early phase as compared to mid or late phase of gestation.

The incidence of most common obstetrical complications viz. dystocia due to abnormal presentation position and posture, uterine torsion and retention of placenta was analyzed and presented in Table 4. The incidence of various complications did not differ significantly $(\mathrm{P}>0.05)$ during last five years, except the incidence of dystocia which increased significantly $(\mathrm{P}<0.05)$ in year 2017 as compared to previous years. The incidence of dystocia in equine is not much documented as compared to cattle and buffalo. The incidence remains higher in the mares with the first time foaling and also in old age. The major causes identified for dystocia in mares are head deviations (40\%), other postural defects, malpositions and monsters (28\%) and breech presentations (8\%) (Jackson, 2004). (McCue and Ferris, 2012) observed that dystocia occurred in $10.1 \%$ of all births and the incidence rate was higher in Thoroughbred mares than in Quarter Horse mares. The most common cause of dystocia was abnormalities of fetal posture. Squires et al. (2013) documented 14.2\% incidence of dystocia in foaling mares as compared to $12.7 \%$ in barren mares. The overall dystocia incidence observed was $13.2 \%$ and there was not any effect of month of parturition or season on the incidence of dystocia (Squires et al., 2013).

The uterine torsion in the mare is an uncommon but lifethreatening event for both the pregnant mare and the fetus (Riggs, 2006). Yorke et al. (2012) reported that uterine torsion occurs typically during mid to late gestation (8-11 months) and was estimated to cause $5-10 \%$ of all equine obstetrical emergencies.

The incidence of retained placenta in mares observed in our study is more or less similar to the previous studies (Shwetz, 2012; Ishii et al., 2013). No association was found between the occurrence of retained placenta, and gestational length, sex of the foal, month of breeding, dam's sire, and time of day of foaling (Sevinga et al., 2004).

\section{CONCLUSION}

It was concluded from the present study that there was not much variations in the reproductive parameters of indigenous breed of mares over the period of last five years. There was increasing number of barren mares and decreasing number of foaling mare which might be attributed to rising reproductive problems in these mares. The early pregnancy period was more prone for pregnancy losses as compared to mid and late pregnancy period. The data generated out of this study would be helpful for planning of breeding strategies and to take suitable measures to curtail the reproductive disorders in equine species. Further, there is necessity of more indigenous breed specific studies on these aspects. 


\section{ACKNOWLEGDEMENTS}

We heartily thanks to the owners of various stud farms in Punjab to maintain record and for providing us valuable data for the completion of this study.

\section{REFERENCES}

Allen, W.R., Brown, L., Wright, M. and Wilsher, S. 2007. Reproductive efficiency of Flatrace and National Hunt Thoroughbred mares and stallions in England. Equine Vet. J., 39(5): 438-45.

Benko, T., Boldizar, M., Dudrikova, K., Novotony, F., Hura, V. and Valocky, I. 2015. Incidence of bacterial pathogens in equine uterine swabs, their antibiotics. Vet. Med., 60(2): 61320 .

Bosh, K.A., Powell, D., Shelton, B. and Zent, W. 2009. Reproductive performance measures among Thoroughbred mares in central Kentucky, during the 2004 mating season. Equine Vet. J., 41(9): 883-88.

Durrani, A.Z. and Kamal, N. 2009. Prevalence of genital tract problems in clinical cases of various species of animals. $J$. Anim. Plant. Sci., 19(3): 160-62.

Hemberg, E., Lundeheim, N. and Einarsson, S. 2004. Reproductive Performance of Thoroughbred Mares in Sweden. Reprod. Domest. Anim., 39: 81-85.

Ishii, M., Aoki, T., Vamakawa, K., Magata, F., Gojo, C., Ito, K. and Nambo, Y. 2013. Relationship between the placental retention time and the reproductive performance at the foal heat in Thoroughbred and a comparison with heavy draft. $J$. Equine Sci., 24(2): 25-29.

Jackson, P.G.G. 2004. Handbook of Veterinary Obstetrics. $2^{\text {nd }}$ edition, W.B. Saunders Company Philadephia, pp. 112-120.

Katila, T., Reilas, T., Nivola, K., Peltonen, T. and Virtala, A. 2010. A 15 years survey of reproductive efficiency of Standardbred and Finnhorse trotters in Finland- descriptive results. Acta Vet. Scand., 52: 40-51.

Laugier, C.,Foucher, N., Sevin, C., Leon, A. and Tapprest, J. 2011. A 24-year retrospective study of equine abortion in Normandy (France). J. Equine Vet. Sci., 31(3): 116-23.

Livestock census. 2014. Salient feature of $19^{\text {th }}$ livestock census. Press Information Bureau, Ministry of Agriculture and farmer's welfare, Government of India.
McCue, P.M. and Ferris, R.A. 2012. Parturition, dystocia and foal survival: a retrospective study of 1047 births. Equine Vet. J., 44(41): 22-25.

Morris, L.H.A. and Allen, W.R. 2002. Reproductive efficacy of intensively managed thoroughbred mares in new market. Equine. Vet. J., 34: 51-60.

Riggs, L.M. 2006. How to perform non-surgical correction of acute uterine torsion in the mare. In Proceedings of the Annual Convention of the American Association of Equine Practitioners, 52: 256-58.

Sairanen, J., Nivola, K., Katila, T., Virtala, A.M. and Ojala, M. 2009. Effects of inbreeding and other genetic components on equine fertility. Animals., 12(3): 1662-72.

Sevinga, M., Barkema, H.W., Stryhn, H. and Hesselink, J.W. 2004. Retained placenta in Friesian mares: incidence, and potential risk factors with special emphasis on gestational length. Theriogenology., 61(5): 851-59.

Sharma, S., Dhaliwal, G.S. and Gosal, N.S. 2011. The impact of uterine therapies on reproductive efficiency in Thoroughbred mares; the possible effect of mare age and reproductive status. Vet. Arh., 81(2): 163-73.

Sharma, S. 2005. Fertility indices of stud farms in Punjab and applicability of immunomodulators as an alternative therapy for endometritis in mare. Thesis submitted to Punjab Agricultural University, Ludhiana, Punjab, India.

Sharma, S., Dhaliwal, G.S. and Dadarwal, D. 2010. Reproductive efficiency of Thoroughbred mares under Indian subtropical conditions: A retrospective survey over 7 years. Anim. Reprod. Sci., 117(3-4): 241-48.

Shwetz, C. 2012. Retained placenta in mares. Alberta Farmers Express in Horse Health Livestock news, 10.

Smith, K.C., Blunden, A.S., Whitwell, K.E., Dunn, K.A. and Wales, A.D. 2003. A survey of equine abortion, stillbirth and neonatal death in the UK from 1988 to 1997. Equine Vet. J., 35(5): 496-501.

Squires, E.L., Hughes, S.E., Ball, B.A., Troedsson, M.H.T. and Stowe, J. 2013. Effect of season and reproductive status on the incidence of equine dystocia. J. Equine Vet. Sci., 33(5): 375 .

Yorke, E.H., Caldwell, F.J. and Johnson, A.K. 2012. Uterine torsion in mares. Compendium on Continuing Education for Practising Veterinarian., 34(12): E2. 